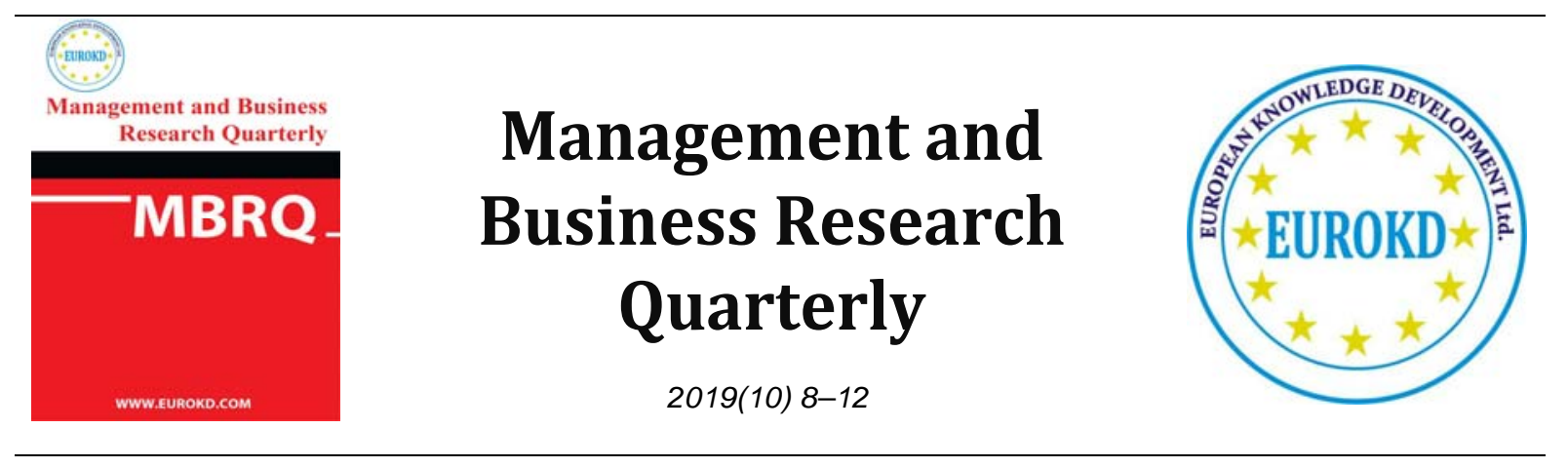

\title{
Competition Policy in Georgia - The Major Phases of Development
}

\author{
Nika Asanidze \\ PhD Student of Economics, Ivane Javakhishvili Tbilisi State University, Georgia
}

Received 17 May 2019

Accepted 26 June 2019

\begin{abstract}
The article analyzes and discusses the possibilities of competition policy in Georgia. The study uses economic analysis. The article based on the facts of the Georgian market. Nowadays, Georgia has a highly liberalized economy with few formal legislative and administrative barriers. Laws regulating competition in Georgia were repealed in 2005. This created risks of well-established market players engaging in anti-competitive practice and abusing their market power. It is clear that the Competition Agency will now face a number of difficulties and challenges when enforcing the Law. The motivation to study competition policy of Georgia and its major phases of development is the step to describe 25 years period of the competition policy in Georgia. The results of the research paper constitute in the usage of theoretical conclusions and in further recommendations. With this being said, recommendations presented in the work will significantly contribute and help researchers expand their scope of research in the above-mentioned field.
\end{abstract}

Keywords: Competition, Competition Policy, Competition History

\section{Introduction}

The economic transformation of newly independent states, their structural demolition, and reformation of national economic systems alongside with their transition into modern western-type market is related to an exceptionally complex, versatile and long-term process. There is no doubt that the transition of the national economic system into the new market-oriented system, including Georgia, requires large material as well as human resources, especially, if we don't consider the 
concentration of necessary powers and available capabilities in order to achieve the abovementioned goal. Hence, it should be noted, that in such processes innovative economy plays a main and important role. It is noteworthy to mention, that in this very spot, arises the necessity to facilitate and promote competition - as only in the presence of fair competition, companies attempt to implement innovations. Such innovations develop not only a single sector of the economy but the economy as a whole. In the modern economy, innovations are one of the key factors in the growth of competitiveness. In the absence of competition, companies will have no motivation to introduce new production methods as well as present new products to the market. Coming from it, the presence of competition is vital for the modern society and hence the actuality of given topic is based on the aforementioned. As it is known, the market economy is an economic system where individuals are independent and they base the main means of production on their independent decisions. In this type of economy, two main forces - private economic interest and competition play a major role. Therefore, in this survey, the ways of improving and optimization of the competition mechanism from different points of view were discussed. It is noteworthy that one of the main goals of the competition is - for the economic agents to gain advantage and maximum profit from operating on the same relevant market. Of course, healthy competitiveness is the main factor for rapid growth in economy. The more competitive market is the more obtained the society is.

\section{Key levels of Competition Policy development in Georgia}

New legal basis was necessary to be created in all fields that would directly affect the economic condition, for which creation of appropriate, consistent competition legislation and its further development was important. First years of independence turned out to be hard for Georgia Just like in many post-socialist countries. Georgia joined the World Bank and IMF in 1992 and began reform program in cooperation with institutions shortly thereafter (Papava, 1995, p. 55).

Main goal of our article is to describe main stages of development of competition policy from beginning till present. It's evident that the competition law and competition policy should not contradict international standards. Therefore, this research describes and analyses examples of competition law in European countries compared with the corresponding legal basis of Georgia. It also outlines results of projects implemented as a result of cooperation with European institutions and other international organizations in Georgia, and it shows positive results. Finally we analyze Georgian competition policy in unified framework and represent results obtained in this period.

Like in the total majority of post-socialist countries, transition to the market economy in Georgia faced major challenges. It is evident that after gaining independence there was necessary to be created new legal basis. Competition law is considered as a constitution of economic system and it serves as one of the key tool for development of free trade and market economy. Taking in consideration its urgency legal basis for competition policy was initiated in 1992. First normative act in Georgia concerning competition was issued on March 17, 1992 titled as "on Some Measures for Demonopolization of Business Activities in the Republic of Georgia", the act was issued in the form of Resolution N 323. Another Decree "on Restriction of Monopolistic Activities and 
Promotion of Competition" was issued. Later, in 1996 Parliament of Georgia issue the law "on Monopolistic Activities and Competition" necessity of issuing such legislative acts occurred as a result of events developed in 1995. All legal acts should be in correspondence with the constitution. "State should promote free entrepreneurship and development of competition. Monopolistic activities are prohibited, except the cases allowed by the law. Consumer rights are protected by law" (Sec. 2, Art. 30) in the same period laws "on Protection of Consumer Rights" (1996) and "on Advertisement" (1998) were issued, these laws equipped Antimonopoly Authority with additional functions and enabled to operate with full capacity (Asanidze, 2017, p. 44). Above events were followed by finalization of processes necessary for implementation of the law "on Monopolistic Activities and Competition".

Simultaneously different normative acts were issued directly, or indirectly connected to the Antimonopoly Authority and created opportunity to improve current situation. For example: 1998 Order of the President of Georgia "on the State Mechanisms for Regulating Natural Monopolies", 2000 Order of the President of Georgia "on State Register of Economic Agents with Monopolistic Status Acting on Commodity Markets of Georgia" and 2002 Order of the President of Georgia "on Arranging Inspection by State Antimonopoly Authority of Georgia".

Established policy resulted in the steps forwarded for recovery of the market, proved in conclusions of different international organizations. However, law "on Monopolistic Activities and Competition" was changed in this period on the base of which communications and energetics were excluded from the control of Antimonopoly Authority, this policy led to the processes started later. From December 2004, number of employees was reduced in the institution implementing competition policy in the country, from that moment course started in 1992 was refused. It was result of fundamental change of economic development in the country. We can assume that its formation finalized on June 3, 2005 by issuing law of Georgia "On Free Trade and Competition". End of these events can be considered to take place in 2005 when the Antimonopoly Authority of Georgia was dissolved.

\section{What is the Role of Competition Policy?}

The importance of free competition has been demonstrated by a number of policy and academic studies. Competition Policy (Anti-trust policy, as it more often called in the US) helps enhance the country's competitiveness on the global market and promote economic welfare. In Particular, free competition leads to a better choice of products and services at lower prices to the benefit of society as a whole and can additionally promote innovation and greater productivity. In addition, competition is one of the priority areas for the successful competition of DCFTA.

Georgia has a highly liberalized economy with few formal (legislative and administrative) barriers. Competition Policy in Georgia is an essential in the efficient working of market. It brings important benefits to the consumer by:

- Encouraging enterprise, innovation, efficiency, and a widening of choice;

- Enabling consumers to buy the goods and services they want at the best possible price;

- Contributing national competitiveness. 
Competition policy seeks to encourage and improve the competitive process, and to ensure consumers feel the benefits of that process. These aims are achieved in practice through competition law.

The main aims of competition policy are to promote competition, make market work better and contribute towards improved efficiency in individual markets and enhanced competitiveness (Asanidze, 2017, p. 419). Competition policy aims to ensure:

- Technological innovation which promotes dynamic efficiency in different markets;

- Effective price competition between suppliers;

- Safeguard and promote the interests of consumers through increased choice and lower price levels.

\section{The Role of Competition Authority in Georgia}

Competition Agency of Georgia, was established in April, 2014 as an Independent Legal Entity of Public Law. The Main objectives of the Agency are:

- Implementation competition policy, safeguard competitive environment in the country, and accordingly, detect and eliminate illicit anti-competitive conducts in private and public sector;

- Undertake various initiatives for raising public awareness on competition issues and participation of consumers in ensuring competition.

The EU is the main trade partner of Georgia, accounting to almost one third of its trade. The Association Agreement between the EU and Georgia introduce a preferential trade regime - the Deep and Comprehensive Free Trade Area (DCFTA) aimed at increasing market access between the EU and Georgia based on having better-matched regulations. From 2016 Competition Agency of Georgia is beneficial of project from EU, Named: "support to the Georgian Competition Agency" the two-year project is funded by the European Union and implemented by a consortium led by Business@Strategies Europe Since January 2017. The project has three components:

- Strengthening the capacity of the Competition Agency;

- Improving cooperation between the competition Agency and sector regulators;

- Promoting a competition culture in Georgia.

Specific areas of support are:

- Legal and Institutional framework;

- Capacity Building;

- Collaboration with Sector Regulators and other Institutions;

- International Cooperation;

- Competition Culture.

\section{Conclusion}

The importance of free competition has been demonstrated by a number of policy and academic studies. This paper presents a study of competition history of Georgia. The study uses economic 
analyses. The paper also provided specific recommendations which government needs to consider in order to implement effective competition policy. Competition Policy plays a key role in fostering dynamic markets and in stimulating economic growth. That is why for developing countries, like Georgia, to improve competition policy is special. In order, competition agency of Georgia's functioning and enforcement of competition policy to be more effective, relevant legislation should also be refined.

\section{References}

Asanidze N., 2017. Competition policy and its importance for the economy. Press Academia Procedia. Online at http://www.pressacademia.org/archives/pap/v4/54.pdf.

Asanidze N., 2017. Competition policy of Georgia, Major phases of development. Ivane Javakhishvili Tbilisi State University press.

Online at https://www.tsu.ge/data/file_db/economist_faculty/global.pdf.

Fetelava, S., Gogiashvili S., 2012. Economic Competition. Loi, Tbilisi.

Pavapa, V., 1995. The Georgian Economy: Problems of Reforms. Eurasian studies. Online at

http://www.papava.info/publications/problems_of reform.pdf

Japaridze L., Zukakishvili K., Kobadze N., Zhvania N., Gvelesiani Z. Akolashvili M., Sergia N., Momtselidze S. 2019. Georgian Competition Law. New Vision University Press, First edition, Tbilisi. Online at http://newvision.ge/sites/default/files/comp_book_color_final.pdf 